OPEN ACCESS

Edited by:

Susanne Menden-Deuer, University of Rhode Island, USA

Reviewed by:

Jose M. Riascos,

Universidad del Valle, Colombia

Øyvind Fiksen,

University of Bergen, Norway

*Correspondence:

Karolane Dufour karolane.dufour@gmail.com

Specialty section:

This article was submitted to

Marine Ecosystem Ecology,

a section of the journal

Frontiers in Marine Science

Received: 29 July 2016 Accepted: 09 September 2016 Published: 23 September 2016

Citation:

Dufour K, Maps F, Plourde S, Joly P and Cyr F (2016) Impacts of Intraguild Predation on Arctic Copepod

Communities. Front. Mar. Sci. 3:185.

doi: 10.3389/fmars.2016.00185

\section{Impacts of Intraguild Predation on Arctic Copepod Communities}

\author{
Karolane Dufour ${ }^{1 *}$, Frédéric Maps ${ }^{1}$, Stéphane Plourde ${ }^{2}$, Pierre Joly ${ }^{2}$ and Frédéric Cyr ${ }^{3}$ \\ ${ }_{1}^{1}$ Takuvik Joint International Laboratory, Université Laval (Canada) - Centre National de la Recherche Scientifique (France), \\ Québec-Océan and Département de Biologie at Université Laval, Québec, QC, Canada, ${ }^{2}$ Institut Maurice-Lamontagne, \\ Department of Fisheries and Oceans Canada, Mont-Joli, QC, Canada, ${ }^{3}$ Aix-Marseille Université, Université de Toulon, Centre \\ National de la Recherche Scientifique/INSU, IRD, Mediterranean Institute of Oceanography, UM 110, Marseille, France
}

Communities of large copepods form an essential hub of matter and energy fluxes in Arctic marine food webs. Intraguild predation on eggs and early larval stages occurs among the different species of those communities and it has been hypothesized to impact its structure and function. In order to better understand the interactions between dominant copepod species in the Arctic, we conducted laboratory experiments that quantified intraguild predation between the conspicuous and omnivorous Metridia longa and the dominant Calanus hyperboreus. We recorded individual egg ingestion rates for several conditions of temperature, egg concentration, and alternative food presence. In each of these experiments, at least some females ingested eggs but individual ingestion rates were highly variable. The global mean ingestion rate of $M$. longa on $C$. hyperboreus eggs was 5.8 eggs ind ${ }^{-1} \mathrm{~d}^{-1}$, or an estimated $37 \%$ of $M$. longa daily metabolic need. Among the different factors tested and the various individual traits considered (prosome length, condition index), only the egg concentration had a significant and positive effect on ingestion rates. We further explored the potential ecological impacts of intraguild predation in a simple 1D numerical model of $C$. hyperboreus eggs vertical distribution in the Amundsen Gulf. Our modeling results showed an asymmetric relationship in that $M$. longa has little potential impact on the recruitment of $C$. hyperboreus $(<3 \%$ egg standing stock removed by IGP at most) whereas the eggs intercepted by the former can account for a significant portion of its metabolic requirement during winter (up to a third).

Keywords: intraguild predation, copepods, Metridia longa, Calanus hyperboreus, Arctic regions, numerical modeling

\section{INTRODUCTION}

Arctic and subarctic marine food webs are characterized by the presence of large calanoid copepods that channel primary production toward secondary consumers. Copepods have developed life cycle strategies that allow them to thrive in these highly seasonal environments. In the Arctic Ocean, several species of Calanus dominate the mesozooplankton biomass (Head et al., 2003; Hopcroft et al., 2010). During the short productive period in spring and summer, copepods feed on ice algae (when available in ice-covered regions) and phytoplankton and concentrate this energy into lipids, mostly stored as wax ester in hypertrophied oil sacs (Lee et al., 2006). In winter, they survive thanks to those lipid reserves that fuel their reduced metabolism during an extended period of dormancy 
(the diapause). All year long, copepods are an essential food source for many predators such as bowhead whale, little auk, and above all Arctic cod, a cornerstone component of the Arctic food web (Fort et al., 2010; Falardeau et al., 2013; Pomerleau et al., 2014). Thus, communities of large copepods form a critical hub of matter and energy fluxes in Arctic and subarctic marine food webs.

In the Arctic, copepod community biomass is mainly composed of the large species Calanus hyperboreus and Calanus glacialis (adult female median prosome length of 6.7 and $4.1 \mathrm{~mm}$, respectively), the medium-sized Metridia longa $(2.8 \mathrm{~mm})$ and the small Pseudocalanus spp. (1.1 mm) (Darnis et al., 2012). Following the current dynamics, the boreal species C. finmarchicus is also regularly found in marginal Arctic seas, especially in the eastern Greenland Sea and Barents Sea (Conover and Huntley, 1991). Moreover, C. finmarchicus' biogeographic distribution in the surface layer is projected to move even farther northward in response to surface circulation and temperature forcing induced by climate change (Reygondeau and Beaugrand, 2011). The structure and functions of copepod communities are critical from an energetic point of view for marine ecosystems and depend on the actual assemblage of species. From one species to the other, the oil sac size is different and therefore the energetic content differs. C. hyperboreus and $C$. glacialis are bigger and contain more lipids than the boreal C. finmarchicus. Consequently, many small visual predators such as fish larvae and juveniles, would reap a larger energetic reward for a similar harvesting effort, making these Arctic copepod species the preys of choice. Hence, changes in the assemblage of copepods communities could impact marine predators' recruitment, resulting in a form of bottomup control (Mills et al., 2013; Greene and Pershing, 2014). For example, along the West coast of the Spitsbergen island in the Svalbard archipelago, the increase of warm Atlantic water masses that bring along abundant $C$. finmarchicus may have a negative impact on the reproductive success of little auks by reducing the relative abundance of its preferred prey, C. glacialis (Kwasniewski et al., 2010). In order to understand and predict impacts of environmental changes on Arctic marine ecosystems, it is necessary to better understand the mechanisms responsible for the specific assemblages of copepod communities.

In addition to physical forcing, relationships occurring within copepod communities can influence their structures and functions. Species that follow each other and co-occur in a community not only share food and space resources, but also develop complex interactions between them. Intraguild predation (IGP) has been proposed as an ecological strategy that could structure copepod communities (Irigoien and Harris, 2006; Plourde et al., 2009; Darnis, 2013; Melle et al., 2014). This particular type of predation occurs between members of a group of species that share the same food resources (Polis et al., 1989). This phenomenon is widespread across a variety of marine and terrestrial ecosystems and through all taxonomic and trophic levels (Polis et al., 1989; Holt and Polis, 1997; Arim and Marquet, 2004). This complex interaction is particularly interesting since it results in an immediate energy gain for the predator as well as a long term reduction of its competition (Hiltunen et al., 2013).

In copepod populations, survival rate to adulthood is strongly influenced by egg and nauplii mortality (Davis, 1984; Plourde et al., 2009). Egg mortality is particularly high in broadcast spawning species that release their eggs in the water column (Ohman et al., 2004), such as Calanus spp and M. longa. Although predominantly considered to be herbivorous, most calanoid copepod species have a flexible diet and can be omnivorous or even cannibalistic (Landry, 1981; Ohman and Hirche, 2001; Bonnet, 2004; Basedow and Tande, 2006). These species usually generate a filtration current to obtain small prey, essentially phytoplankton and micro-zooplankton, or cruise through the water and attack when a prey is detected (Kiørboe, 2013). Thus, they can consume eggs and young nauplii stages with limited mobility.

Cannibalism on eggs and nauplii can control the phenology of C. finmarchicus recruitment (Ohman and Hirche, 2001). It is therefore likely that IGP can impact recruitment as well as influencing the temporal succession of dominant species (Irigoien and Harris, 2006). In environments as contrasted as the Beaufort Sea and the St-Lawrence estuary, reduced C. hyperboreus recruitment and abundance co-occurred with an increase in M. longa abundance (Plourde et al., 2002; Darnis, 2013). During the time of peak egg production by C. hyperboreus, the gut of individual $M$. longa is often observed to be orange, a particularity linked to the probable ingestion of lipid-rich C. hyperboreus eggs (Conover and Huntley, 1991). Hence it has been hypothesized that $M$. longa individuals that remain active at intermediate depths throughout winter (no diapause) could intercept and ingest buoyant $C$. hyperboreus eggs that are spawned in deep waters (Plourde et al., 2003; Darnis, 2013). Given that $M$. longa population dynamics resources are scarce in winter, lipid-rich eggs could represent an important energy source for such an omnivorous (opportunistic) species. Later in early spring, numerous C. hyperboreus and C. glacialis that emerge from diapause and ascend toward the surface ahead of the phytoplankton bloom could also be feeding on eggs and young nauplii stages. Consequently, IGP could impact the recruitment of the true Arctic C. hyperboreus.

Surprisingly, only few studies have been conducted on predation within calanoid copepod communities (Landry, 1981; Huntley and Escritor, 1992; Bonnet, 2004; Basedow and Tande, 2006; Vestheim et al., 2013). The majority of the studies targeted cannibalism and while none was focused on IGP between the dominant Arctic species $M$. longa and C. hyperboreus, Huntley and Escritor (1992) reported ingestion rates of the vicariant species $M$. gerlachei on eggs of the dominant Antarctic Calanoides acutus in the Austral Ocean. In all experiments, ingestion rates on eggs (and nauplii) vary according to their concentration. The influence of alternative food source on ingestion produced ambiguous experimental results. On one hand, experiments with female $C$. pacificus suggest a switch between herbivorous and carnivorous behavior that depends on the relative abundances of phytoplankton and their own nauplii (Landry, 1981). On the other hand, experiments with C. finmarchicus have shown that ingestion rates on its own 
nauplii are independent of the ambient algae concentration (Basedow and Tande, 2006).

Copepod community models have been developed with a focus on development, growth and competition for food resources (Record et al., 2012, 2013). However, community level processes involving interspecific interactions such as IGP have not yet been implemented into these models. In order to provide a better understanding of IGP and to provide a better parameterization for models of copepod communities, we conducted laboratory experiments that quantified the ingestion of copepod eggs by some of the dominant Arctic copepod species, $M$. longa and C. hyperboreus. We further conducted a simple numerical experiment in order to assess the potential ecological implications of our findings in Arctic marine ecosystems. Copepods were sampled in the Lower St-Lawrence estuary (LSLE) and feeding experiments on eggs were conducted under different conditions of temperature, egg concentration, and alternative food availability.

\section{METHODS}

\section{Area of Study and Sampling}

The LSLE is the southernmost sea directly influenced by Arctic water masses and that presents Arctic features in the North Atlantic (Figure 1). Arctic water masses enter in the Gulf of St-Lawrence (GSL) by the Strait of Belle Isle in the North, transporting Arctic copepods species such as C. hyperboreus, C. glacialis, and M. longa. Warmer North Atlantic water masses enter the system by Cabot Strait in the South and carry along boreal species such as $C$. finmarchicus. Both Arctic and temperate species thrive in the GSL system where cold and warm water masses are segregated vertically between the thin seasonal surface layer, the cold intermediate layer renewed locally each winter (core temperatures can be negative) and the deep Atlantic layer (between 4 and $5^{\circ} \mathrm{C}$ ). Colder water masses dominate the eastern and northern parts of the Gulf and the deep lower Estuary where upstream tidal pumping brings cold and nutrient-rich waters to the surface, whereas warm surface waters (up to $20^{\circ} \mathrm{C}$ ) develop throughout the summer over the shallow southern half of the Gulf (Saucier et al., 2003; Le Fouest et al., 2005). These particular water masses and species mix make the LSLE an exceptional experimental model to study IGP in the context of the rapid environmental changes that the Arctic is currently facing. Zooplankton was sampled in the LSLE $\left(48^{\circ} 40^{\prime} \mathrm{N}, 68^{\circ} 35^{\prime} \mathrm{W}\right)$ in October 2014 with a vertical plankton net $(158 \mu \mathrm{m}$ mesh size, $1 \mathrm{~m}$ diameter) at 125 or $200 \mathrm{~m}$ from the surface at a towing speed of $0.5 \mathrm{~m} \mathrm{~s}^{-1}$. The catch was diluted into $4 \mathrm{~L}$ jars filled with filtered seawater and maintained close to ambient temperature at 5 to $6^{\circ} \mathrm{C}$ in coolers during transport to the laboratory (less than an hour).

In a subsequent numerical experiment, we applied our observations to a truly Arctic environment, the Amundsen Gulf. The Amundsen Gulf is located in the Canadian territory of Nunavut at about $71^{\circ} \mathrm{N}$ and bordered by Banks Island and Victoria Island. It connects south-eastern Beaufort Sea to the Canadian archipelago (Figure 1). The Amundsen Gulf water masses are generally cold (around $0^{\circ} \mathrm{C}$ ) and are mainly discriminated by their different salinities: the Polar-Mixed Layer from the surface to c.a. $50 \mathrm{~m}$ ( $\mathrm{S} \sim 31.6$ ), the Pacific Halocline below until $200 \mathrm{~m}(32.4<\mathrm{S}<33.1)$ and the slightly warmer Atlantic Layer below $200 \mathrm{~m}$ (S 34) (Carmack and Macdonald, 2002). The Gulf covers about $60,000 \mathrm{~km}^{2}$ and the maximum

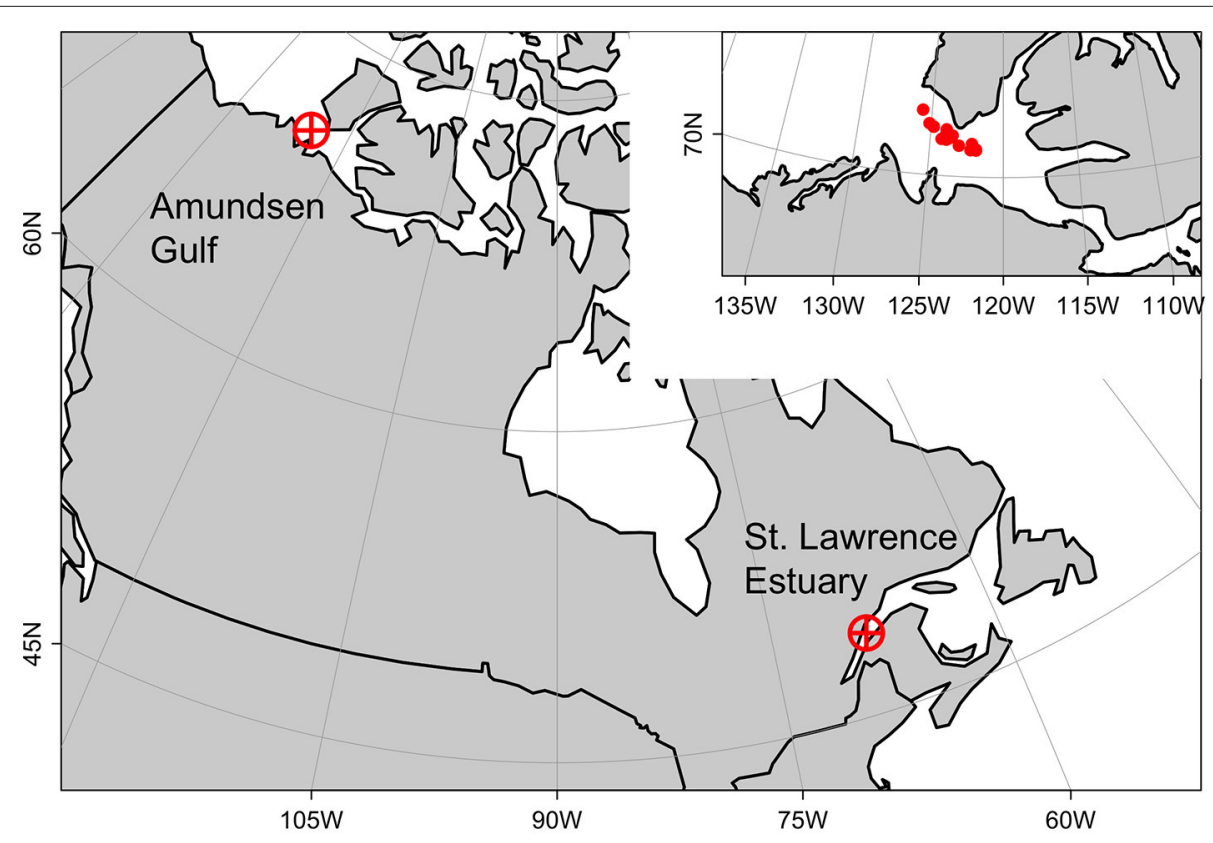

FIGURE 1 | Studied area. Arctic copepod species used in incubation experiments were sampled from the St. Lawrence Estuary. Environmental and biological forcing used in numerical experiments came from the Amundsen Gulf. Position of mean individual profiles shown in inset, upper-right corner. 
depth of this large channel is $630 \mathrm{~m}$. In winter, it is entirely ice-covered except for sporadic polynyas and flaw leads and the spring ice-breakup his highly variable (Galley et al., 2008).

\section{Live Animal Sorting}

Owing to the harsh conditions at sea during winter over the LSLE, copepods were sampled at the end of October 2014 prior to the beginning of $C$. hyperboreus reproduction and the formation of dense sea ice. Plourde et al. (2003) have previously shown, for a similar experimental setup, that capture and handling of C. hyperboreus females triggered gonad maturation, leading to egg production a few weeks after collection and approximately a month earlier than expected according to the in situ timing. A visual inspection of appendages and behavior under a binocular microscope allowed us to select adult female $M$. longa and C. hyperboreus in good condition from the live samples, within $48 \mathrm{~h}$ of the catch. Animals were kept in the dark between 3 and $5^{\circ} \mathrm{C}$ in groups of 25 to 50 in $1 \mathrm{~L}$ beakers equipped with egg separators (mesh size $=333 \mu \mathrm{m}$ ) and filled with filtered seawater. Female $M$. longa were fed with solutions of concentrated diatoms Thalassiosira weissflogii (Instant Algae ${ }^{\circledR}$ TW 1200), whereas female $C$. hyperboreus where not fed since egg production is entirely fuelled by internal lipids during the dormant part of their life cycle. The beakers were inspected daily for egg production for about a month until female $C$. hyperboreus spawned enough eggs to start the experiments.

\section{Predation Experiments}

Within $48 \mathrm{~h}$ of the start of the experiment, individuals used as predators were photographed laterally using a PixeLINK camera of $5 \mathrm{Mb}$ (PL-E425CU) mounted on a LEICA MZ6 stereoscope. In order to minimize stress, individuals were kept in cooled seawater until the very moment that the picture was taken and gently manipulated with handling needles. Prosome length (distance between the tip of the cephalosome and the tip of the last thoracic segment), prosome area, oil sac length, and area were measured with the software ImageJ v. 1.49. The condition index was estimated as the oil sac area divided by the prosome area of the individual in order to give an indication of its lipid content. Predators' carbon content was estimated from species and stagespecific seasonal relationships between individual carbon mass and prosome length (Forest et al., 2010). The photographed animals were then placed individually in $45 \mathrm{~mL}$ Petri dishes filled with filtered seawater and equipped with egg separator (mesh size $=333 \mu \mathrm{m}$ ) for acclimation at the experimental temperatures.

Experiments were carried in an atmosphere-controlled chamber in November 2014 with female M. longa fed with C. hyperboreus eggs. Predators were placed individually in a bottle ( 1.35 or $2.37 \mathrm{~L})$ filled with filtered seawater containing a precise number of eggs spawned within the previous $48 \mathrm{~h}$. Bottles were turned upside down once per minute on a rotating wheel in order to maintain the eggs in suspension. Manipulations were conducted under a dimmed red light and the experiments were carried in the dark. Incubation time was kept relatively short (less than $24 \mathrm{~h}$ ) in order to avoid a complete consumption of the eggs and hence a failure to accurately estimate ingestion rates. It also varied according to incubation conditions, with longer incubation times for lower egg concentration (lower encounter probability between eggs and the predator). After 4 to $22 \mathrm{~h}$, the contents of the bottles were filtered with a $73 \mu \mathrm{m}$ sieve and the remaining eggs were counted. A minimum of two controls without predator for each treatment was set up in order to check the accuracy of the egg recovery method. The status of each individual was verified at the end of the experiment. Ingestion rates were discarded for the few dead individuals, and the sluggish or unhealthy-looking ones as well.

We tested the effect of temperature on $M$. longa ingestion of $C$. hyperboreus eggs. Incubations were carried at 1, 4, and $8^{\circ} \mathrm{C}$ to reflect the potential range of in situ water temperature encountered by this species between the Arctic and subarctic regions. Unfortunately, we could not test for negative water temperatures. In order to characterize functional responses, we tested the effect of $C$. hyperboreus egg concentration on $M$. longa ingestion rate. We were not aware of actual data about in situ C. hyperboreus egg concentrations in the water column, but we estimated it to be low (Huntley and Escritor, 1992). Hence we chose concentrations of 5, 10, 20, and $30 \mathrm{egg} \mathrm{L}^{-1}$. Finally, we checked whether there was an influence of alternative food availability, by adding an additional food source in the form of concentrated diatoms T. weissflogii (Instant Algae ${ }^{\circledR}$ TW 1200) in half of our replicates. Algae were offered at about $50 \mu \mathrm{g} \mathrm{C}$ $\mathrm{L}^{-1}$ according to cell concentration determined with a Hausser Bright-Line Hemacytomer (couting chamber) and carbon to volume relationships for diatoms (Menden-Deuer and Lessard, 2000).

\section{Estimation of Ingestion Rates}

The instantaneous feeding rate on eggs $g\left(\mathrm{~h}^{-1}\right)$ was derived from an exponential equation (Båmstedt et al., 2000):

$$
g=\frac{\ln \left(\frac{E_{f}}{E_{0}}\right)}{t}
$$

where $E_{0}$ and $E_{f}$ are respectively the egg concentration at beginning and the end of experiment $\left(\right.$ egg $\left.\mathrm{L}^{-1}\right)$ and $t$ is incubation time (h). The number of $C$. hyperboreus eggs obviously did not increase during the experiments, and experiment duration was not long enough for hatching to occur (no nauplii was ever found in any of the control or experiment bottles).

We deduced the clearance rate $F\left(\mathrm{~L}\right.$ ind $\left.{ }^{-1} \mathrm{~h}^{-1}\right)$, which corresponds to the volume of water processed assuming $100 \%$ capture efficiency and a homogeneous food concentration, from both $g$ and the volume of the incubation bottle $V(\mathrm{~L})$ :

$$
F=g \times V
$$

Finally, we obtained the ingestion rate $I\left(\operatorname{egg}\right.$ ind $\left.^{-1} \mathrm{~h}^{-1}\right)$ with:

$$
I=F \times[E]
$$

where $[E]$ is the average egg concentration as given by:

$$
[E]=\left(E_{0} \times \frac{1-e^{(-g \times t)}}{g \times t}\right)
$$


Daily ingestion rates where assumed to be 24 times the hourly rates since $M$. longa is known to be active and swimming almost continuously (Hirche, 1987). Egg ingestion rates were then converted in carbon units using an egg carbon content of

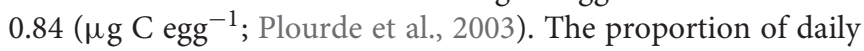
metabolic needs (\%) satisfied by egg ingestion was estimated from the ratio of carbon ingestion rate $I_{C}=0.84^{*} I\left(\mu \mathrm{g} \mathrm{C}\right.$ ind $^{-1}$ $\left.\mathrm{d}^{-1}\right)$ and a mean and constant respiration rate $\left(\mu \mathrm{g} \mathrm{C}\right.$ ind $\left.{ }^{-1} \mathrm{~d}^{-1}\right)$ measured by Seuthe et al. (2006).

\section{Data Analysis}

The number of ingested eggs followed a Poisson distribution (an asymmetric right-skewed distribution of discrete values). Hence, in order to minimize estimating errors, a generalized linear model (GLM) for Poisson distribution was used to predict the number of eggs ingested (EI) (the raw data) according to temperature $(T)$, egg concentration $(E)$, presence of additional food source $(A C)$, prosome length $(P L)$, and condition index $(C I)$ of the predator. Bottle volume $(V)$ and duration of experiment $(D)$ were taken into account by using them in an offset term. Several models were tested (with and without interactions) and we computed Akaike's information criterion corrected for overdispersion (QAIC) as a decision-support metric. The GLMs formulae were of the form (here is the one with all the independent variables but no interactions):

$$
\begin{aligned}
\log \left(\frac{E I}{D \times V}\right)= & \beta_{0}+\left(\beta_{T} \times T\right)+\left(\beta_{E} \times E\right) \\
& +\left(\beta_{A C} \times A C\right)+\left(\beta_{P L} \times P L\right)+\left(\beta_{C I} \times C I\right)
\end{aligned}
$$

where $\beta_{i}$ are the coefficient estimates for each variable. The number of eggs ingested per unit of time and volume can easily be obtained from this model results.

\section{Model of Egg Vertical Distribution}

In order to assess the implications of our findings in the context of Arctic marine ecosystems, we developed a simple water column (1D) model of the vertical distribution of C. hyperboreus eggs in the Amundsen Gulf. The model computed the time evolution of egg concentration at a given depth according to advection and diffusion, gains by egg production and losses by development and predation (Figure 4). The rate of change of egg concentration followed the classical advection-diffusion-reaction formulation (Soetaert and Herman, 2009):

$$
\frac{\partial E}{\partial t}=-w \frac{\partial E}{\partial z}+K \frac{\partial^{2} E}{\partial z^{2}}+P_{z}-I * M+1 / H * E
$$

where the first right-hand side term represents the effect of egg vertical velocity, the second the effect of diffusion and the others several biological reaction terms. More specifically, $E$ was the egg concentration (egg $\mathrm{m}^{-3}$ ), $t$ the time (h), $w$ the egg velocity $\left(\mathrm{m} \mathrm{h}^{-1}\right)$ defined positive downward, $z$ the depth $(\mathrm{m}), K$ the vertical eddy diffusivity coefficient $\left(\mathrm{m}^{2} \mathrm{~h}^{-1}\right), P_{Z}$ the

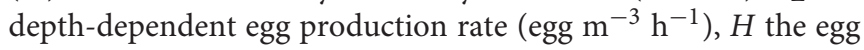
hatching time (h), $\mathrm{M}$ the females $M$. longa concentration (ind $\mathrm{m}^{-3}$ ) and $I$ the ingestion rate by other copepods (egg ind ${ }^{-1}$ $\mathrm{h}^{-1}$ ). The egg velocity $w$ was given by Stokes' law (Visser and Jónasdóttir, 1999):

$$
w=3600 \times \frac{g \times d^{2} \times\left(\rho_{\text {egg }}-\rho_{\text {water }}\right)}{18 \times \mu}
$$

where $g$ is the gravitational constant $\left(9.81 \mathrm{~m} \mathrm{~s}^{-2}\right), d$ is the egg diameter $(\mathrm{m}), \rho_{\text {egg }}$ is the egg density $\left(\mathrm{g} \mathrm{m}^{-3}\right), \rho_{\text {water }}$ is the water density $\left(\mathrm{g} \mathrm{m}^{-3}\right)$ and $\mu$ is the dynamic viscosity of the seawater $\left(1.85 \mathrm{~g} \mathrm{~m}^{-1} \mathrm{~s}^{-1}\right)$, here taken as a constant (Table $\left.\mathbf{1}\right)$.

The source term for eggs $\left(P_{Z}\right)$ came from the average daily production of $C$. hyperboreus population $\left(30,000\right.$ eggs $\left.\mathrm{m}^{-2}\right)$ observed between February and April 2008 in the Amundsen Gulf (Darnis, 2013). C. hyperboreus females released more than $90 \%$ of their eggs during this 3 month-period, while remaining at depths between 200 and $300 \mathrm{~m}$ (Darnis, 2013). As a result, we computed the vertical profile of egg production rate $P_{Z}$ according to a normal distribution whose mean was centered at $250 \mathrm{~m}$, its standard deviation $15 \mathrm{~m}$ and its integral equal to 30,000 eggs $\mathrm{m}^{-2}$ (99.9\% of the eggs were released between 200 and $300 \mathrm{~m}$ ).

The IGP rate $I\left(\mathrm{~h}^{-1}\right)$ exerted on $C$. hyperboreus eggs was simply the product of $M$. longa females' abundance (ind $\mathrm{m}^{-3}$ ) and the individual filtration rate $\left(\mathrm{m}^{3}\right.$ ind $\left.{ }^{-1} \mathrm{~h}^{-1}\right)$ found in our grazing experiments.

Egg hatching time $H(\mathrm{~h})$ followed an empirical Bělehrádek's function obtained from observed hatching times of C. hyperboreus eggs (Jung-Madsen et al., 2013):

$$
H=a \times(T-\alpha)^{-b}
$$

where $T$ was water temperature $\left({ }^{\circ} \mathrm{C}\right), a\left(\mathrm{~d}{ }^{\circ} \mathrm{C}^{-1}\right), \alpha\left({ }^{\circ} \mathrm{C}\right)$ and $b$ constants.

A simple ordinary differential equation framework was not optimal for the modeling of developing eggs because of the "numerical diffusivity" caused by the hatching rate (Gentleman et al., 2008). Simply put, with a development (hatching) rate, the progression through development stages is treated as a continuous process within the population, instead of a discrete event highly synchronized among many individuals. This can

TABLE 1 | Model parameters and references.

\begin{tabular}{llll}
\hline Parameter & Unit & Value & References \\
\hline$H$, egg hatching time & & & JM2013 \\
$a$ & $\mathrm{~d}^{\circ} \mathrm{C}^{-1}$ & 1196 & $\mathrm{JM} 2013$ \\
$\alpha$ & ${ }^{\circ} \mathrm{C}$ & 12.7 & $\mathrm{JM} 2013$ \\
$b$ & - & -2.05 & $\mathrm{JM} 2013$ \\
$d$, egg diameter & $\mathrm{m}$ & $1.92 \times 10^{-4}$ & $\mathrm{JM} 2013$ \\
$P$, egg production & $\mathrm{egg} \mathrm{m}{ }^{-2} \mathrm{~d}^{-1}$ & 30,000 & $\mathrm{D} 2013$ \\
$\rho$ egg, egg density & $\mathrm{g} \mathrm{m}^{-3}$ & $0.6 \times 10^{3}$ (min) & $\mathrm{JM} 2013$ \\
& & $19.4 \times 10^{3}$ (mean) & $\mathrm{JM} 2013$ \\
& & $26.8 \times 10^{3}$ (max) & $\mathrm{JM} 2013$ \\
$\mu$, dynamic viscosity & $\mathrm{g} \mathrm{m}^{-1} \mathrm{~s}^{-1}$ & 1.9 & VJ1999 \\
\hline
\end{tabular}

VJ1999, Visser and Jónasdóttir (1999); D2013, Darnis (2013); JM2013, Jung-Madsen et al. (2013) 
lead to unrealistic and spurious results, such as a small fraction of the simulated egg population that has already hatched after the first time step! In order to prevent this, we used the simple approach of spreading the egg development over 20 numerical stages of equal length (Gentleman et al., 2008) and we further integrated the development throughout theses stages with a flux limiting numerical scheme (Record and Pershing, 2008).

\section{Simulations}

The $1 \mathrm{D}$ water column model was split into $5 \mathrm{~m}$ vertical layers between 0 and $300 \mathrm{~m}$, and the time step of integration was $12 \mathrm{~h}$. For the model forcing, we used physical and biological datasets from the Circumpolar Flaw Lead System Study (CFL; Barber et al., 2011). We only selected profiles from stations that were at least $300 \mathrm{~m}$ deep and located within the Amundsen Gulf. As a result, the physical forcing came from mean vertical profiles of eddy diffusivity coefficient $(K)$, temperature $(T)$, and water density $\left(\rho_{\text {water }}\right)$ obtained at 20 different stations. These stations were sampled in November and December 2007 under dense sea-ice cover with a vertical microstructure profiler (VMP500, Rockland Scientific International). For two long-term stations the number of casts used in the average profile were respectively 24 and 25, whereas at least 5 profiles were used to build the 18 other mean profiles. Missing values in averaged profiles (e.g., near the surface or below $250 \mathrm{~m}$ ) were dealt with according to Equation (1) from Bourgault et al. (2011). Further details about this dataset can be found in their study.

We also used 18 vertical profiles of $M$. longa female abundance obtained with a Hydrobios ${ }^{\circledR}$ multinet sampler. Details of the sampling procedure can be found in Darnis and Fortier (2014). We selected the stations sampled between February and April 2008, during the peak of C. hyperboreus reproduction. The layer thickness for the vertical sampling ranged from 10 to $144 \mathrm{~m}$, with a median of $20 \mathrm{~m}$.

In order to test the sensitivity of the model to both the physical properties of the water column and the vertical distribution of the predators ( $M$. longa) we ran 360 simulations, one for each possible combination of the physical and biological forcing fields. In addition, we ran this ensemble of simulations for three different scenarios of egg density in order to verify the impacts of different egg velocities: the mean (scenario $\left.D_{0}\right)$, minimum $\left(D_{\min }\right)$ and maximum $\left(\mathrm{D}_{\max }\right)$ egg densities observed by Jung-Madsen et al. (2013). Simulations ran for 15 days in order to reach a quasi-steady state where the maximum local rate of change in egg concentration $\delta E / \delta t$ was less than $10^{-6}$.

\section{RESULTS}

\section{Egg Ingestion Rates}

Predation of $C$. hyperboreus eggs by female $M$. longa occurred in each of the incubation experiments. However, in each experiment there was high individual variability and several individual incubations showed no egg ingestion. After discarding incubations within which dead or unhealthy individuals were found at the end of the experiment, for each treatment approximately 8 individual replicates out of the initial 10 were used for further analyses. The frequency distribution of ingestion rates was positively skewed, i.e., the median value was lower than the mean. The global mean ingestion rate of $C$. hyperboreus eggs by $M$. longa was 5.8 eggs ind ${ }^{-1} \mathrm{~d}^{-1}(S E=0.57, n=141)$ and the median was 3.7 eggs ind $\mathrm{d}^{-1} \mathrm{~d}^{-1}$ (Figure 2). In terms of carbon, the mean ingestion rate was $4.9 \mu \mathrm{g} \mathrm{C}$ ind $^{-1} \mathrm{~d}^{-1}$ and the median $3.1 \mu \mathrm{g} \mathrm{C}$ ind ${ }^{-1} \mathrm{~d}^{-1}(S E=0.48, n=141$; Figure 2). C. hyperboreus eggs constituted an energy-rich food source $(0.84$ $\mu \mathrm{g} \mathrm{C}$ egg $^{-1}$; (Plourde et al., 2003) and the average daily ration of $M$. longa females feeding on C. hyperboreus eggs was $37 \%$ of their estimated metabolic needs based on respiration rates $(S E=4, n=141)$. Individual variability resulted in a contrasted pattern where about a quarter of $M$. longa did not ingest any eggs, while an equivalent proportion filled more than $50 \%$ of their daily energetic requirements through egg ingestion. Some individuals actually largely exceeded their daily metabolic needs (i.e., over $100 \%$, Figure 2), even when eggs were offered at low concentrations.

\section{Influence of Incubation Conditions}

According to the GLM analysis, presence of additional food source, prosome length, or condition index of the individuals had no discernable effect on egg ingestion (Table 2). The only predictor that improved the model and that significantly affected the number of eggs ingested by $M$. longa was egg concentration (Figure 3). In the full model with no interactions, temperature seemed to have a significant negative effect on ingestion rates (Table 2). However, in the model that only kept egg concentration and temperature as independent variables, the influence of temperature and the interaction term between them did not remain significant. Moreover, the size effect of the temperature and interaction term coefficients was small compared to the impact of egg concentration and the QAIC values were very close between the models. Hence, we decided to use the simplest model with only egg concentration as predictor of egg ingestion (Figure 3). We did not observe any feeding saturation for the range of egg concentrations offered.

\section{Simulated Egg Vertical Distribution}

The velocity of C. hyperboreus eggs estimated with Equation (7) ranged between -9 and $-4.1 \mathrm{~m} \mathrm{~d}^{-1}$ for the mean egg density scenario $\left(D_{0}\right)$ over the 20 physical forcing profiles. Negative velocities meant that eggs were positively buoyant, from the bottom of the water column up to the surface. Egg velocity was dependent on the water density profile and it decreased slowly with decreasing depth (Figure 4). This pattern was conserved among the 20 physical forcing profiles whose overall variability was low. Egg velocity was strongly influenced by egg density itself. C. hyperboreus egg density is highly variable, both between individual females and within clutches of the same female (JungMadsen et al., 2013). When we used the minimal egg density (scenario $D_{\min }$ ) the velocity tripled to range between -26.2 and $-21.3 \mathrm{~m} \mathrm{~d}^{-1}$, whereas for maximal egg density (scenario $\mathrm{D}_{\max }$ ) the associated velocity was not negative throughout the water column. The egg velocity ranged between -2.3 and $2.6 \mathrm{~m} \mathrm{~d}^{-1}$ with a converging depth of neutral buoyancy around $100 \mathrm{~m}$.

Egg velocity was critical for egg vertical distribution. In the ensemble of simulations for scenario $\mathrm{D}_{0}$, egg vertical 


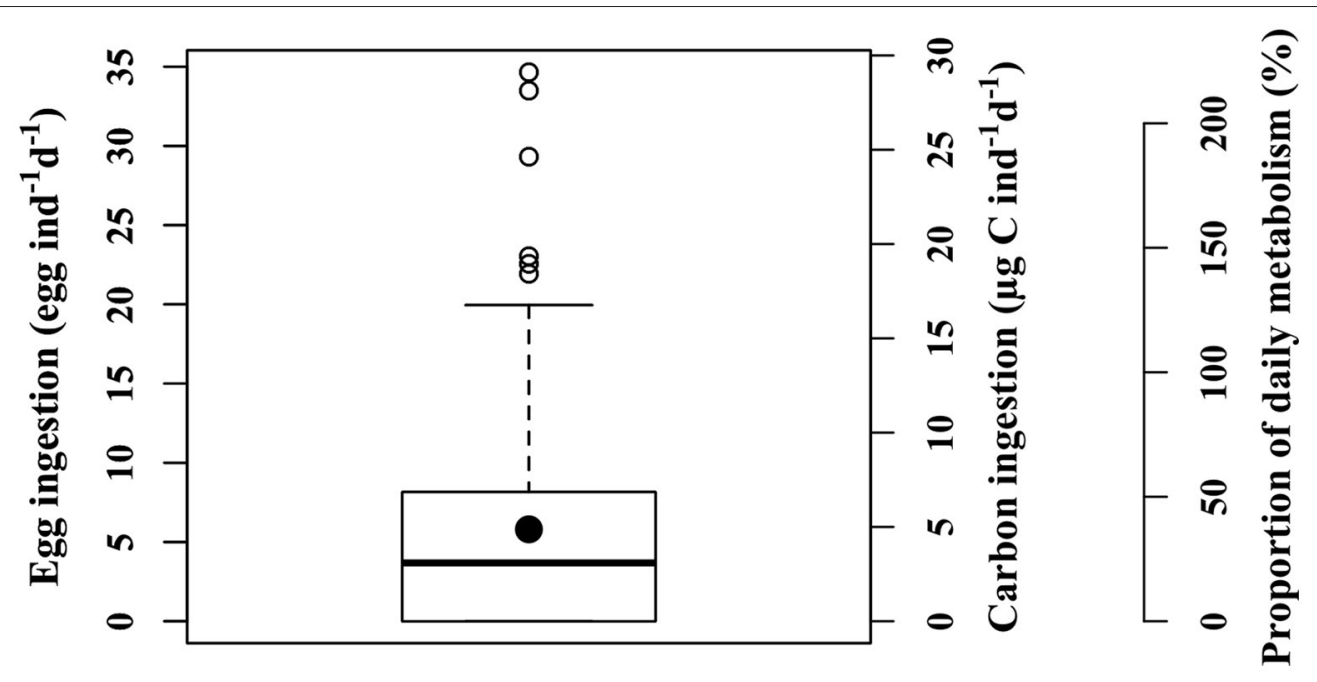

FIGURE 2 | Ingestion rates of female $M$. longa on C. hyperboreus eggs from all experiments according to different units: number of eggs, carbon content, and proportion of daily metabolic needs (see text). Thick black line: median; black circle: mean; box: range between the first and third quartiles (IQR); whiskers: \pm 1.5 IQR; open circles: outliers.

distributions showed higher concentrations between 150 and $275 \mathrm{~m}$ and peaked around $225 \mathrm{~m}$ to reach about 3000 eggs $\mathrm{m}^{-3}$ (or 3 eggs $\mathrm{L}^{-1}$ ) once the simulation reached its steady state (Figure 4). For scenario $D_{\max }$, the denser eggs ascend only slightly in the water column before hatching. They remained concentrated between 200 and $300 \mathrm{~m}$ with a maximum egg concentration a little less than 4000 eggs $\mathrm{m}^{-3}$ near $250 \mathrm{~m}$ (Figure 4). Contrarily, in the $\mathrm{D}_{\text {min }}$ scenario, eggs moved rapidly upward and some even managed to reach the first $5 \mathrm{~m}$ of the water column to attain a concentration of a little less than 300 eggs $\mathrm{m}^{-3}$ (Figure 4). Eggs where spread over the entire column and concentration peaked above $160 \mathrm{~m}$ at about 1200 eggs $\mathrm{m}^{-3}$.

\section{Impact of $M$. longa Predation on C. hyperboreus Eggs}

For each egg density scenario tested, the proportion of egg biomass eaten by $M$. longa was more sensitive to the profiles of $M$. longa abundance than to the physical forcing (see Figure 5 for scenario $\mathrm{D}_{0}$ ). Over the ensemble of 360 simulations of the $\mathrm{D}_{0}$ scenario, the percentage of $C$. hyperboreus egg standing stock ingested by $M$. longa ranged between 0.1 and $1.1 \%$ with most of the values being in the low end (Figure 6). The percentage of egg standing stock ingested by $M$. longa varied between 0.2 and $3.2 \%$ for scenario $D_{\min }$ and between 0 and $0.8 \%$ for maximal egg density (scenario $\mathrm{D}_{\max }$; Figure 6).

This modest impact of $M$. longa IGP is hardly noticeable between the egg concentration profiles simulated with and without egg predation, even for the combination of physical conditions and $M$. longa profiles that lead to the maximum difference (Figure 7). The corresponding daily egg ingestion of the whole population of $M$. longa ranged between a little more than 1 to almost 20 eggs $\mathrm{m}^{-3} \mathrm{~d}^{-1}$ (Figure 7). It is noticeable, though, that such egg ingestion values could allow M. longa individuals to satisfy almost $10 \%$ of their metabolic
TABLE 2 | Results from the generalized linear models (GLM) fitted to predict the number of $C$. hyperboreus eggs ingested by female $M$. longa according to egg concentration $(E)$, temperature $(T)$, alternative food source $(A C)$, condition index $(C I)$, prosome length $(P L)$, and interactions between the terms.

\begin{tabular}{|c|c|c|c|c|c|}
\hline GLM & Predictor & $\beta$ & $S E$ & P-value & QAIC \\
\hline \multirow[t]{6}{*}{$E, T, A C, C l, P L$} & Intercept & -1.870 & 3.340 & ns & 215 \\
\hline & $E$ & 0.068 & 0.012 & 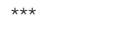 & \\
\hline & $T$ & -0.093 & 0.040 & * & \\
\hline & $A C$ & 0.0007 & 0.004 & ns & \\
\hline & $\mathrm{Cl}$ & -0.927 & 1.118 & ns & \\
\hline & $P L$ & -0.300 & 1.165 & ns & \\
\hline \multirow[t]{4}{*}{$E, T, E \times T$} & Intercept & -3.365 & 0.379 & 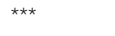 & 208 \\
\hline & $E$ & 0.111 & 0.024 & 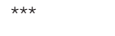 & \\
\hline & $T$ & 0.031 & 0.078 & ns & \\
\hline & $E \times T$ & -0.008 & 0.004 & $n s$ & \\
\hline \multirow[t]{2}{*}{$E$} & Intercept & -2.944 & 0.199 & $\star \star \star *$ & 215 \\
\hline & $E$ & 0.053 & 0.009 & $\star \star * *$ & \\
\hline
\end{tabular}

Estimated coefficients b, standard error SE, $P$-values $\left({ }^{* \star \star} P<0.001 ;{ }^{\star \star} P<0.01 ;{ }^{*} P<0.1\right.$; ns not significant) and Akaike's information criterion corrected for overdispersion QAIC. Model entry in bold indicates the one selected for further numerical experiments.

needs according to respiration rates from Seuthe et al. (2006), or up to $37 \%$ if we consider the lower respiration rates reported by Hirche (1987).

\section{DISCUSSION}

\section{Individual Variability}

Our results show high individual variability of egg ingestion rates, with a quarter of all the individuals not ingesting any eggs and about the same proportion satisfying more than half of 


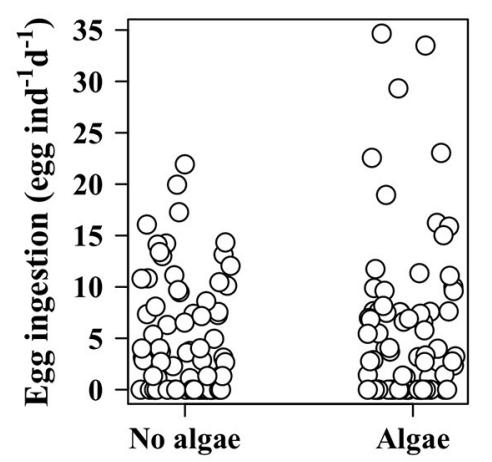

Alternative food source

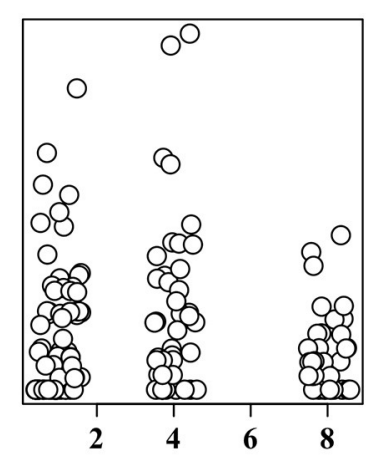

Temperature $\left({ }^{\circ} \mathrm{C}\right)$

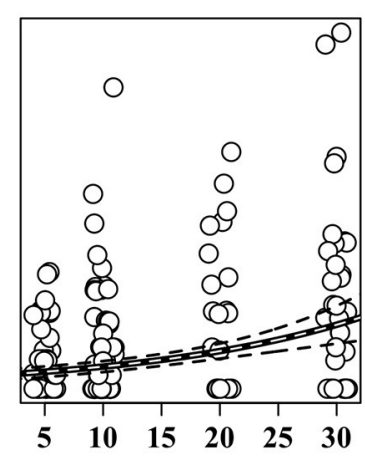

Egg concentration $\left(\operatorname{egg} \mathrm{L}^{-1}\right)$

FIGURE 3 | Ingestion rates of female M. longa on C. hyperboreus eggs according to the presence of alternative food source (left panel), temperature (middle panel), and egg concentration (right panel). Points are jittered to reduce overlap. Black and white line is the prediction of the mean from the selected generalized linear model (see text); dotted black lines are the corresponding 95\% confidence intervals.

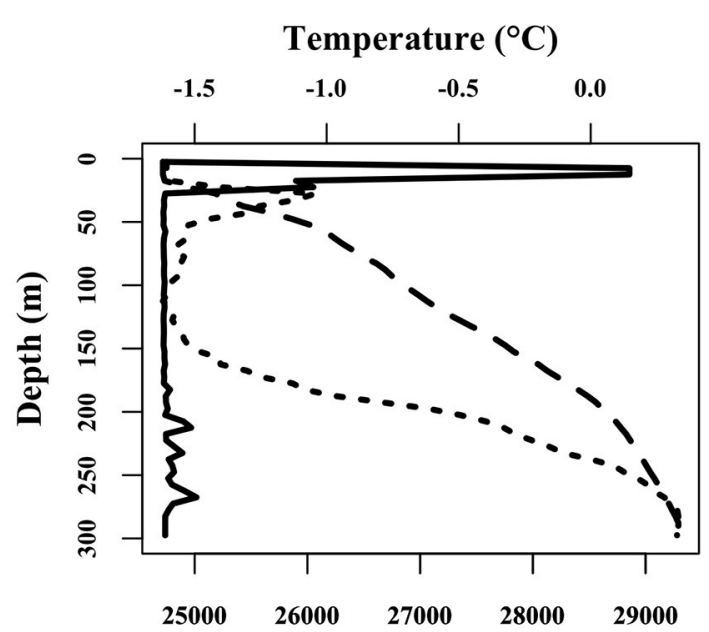

Density anomaly of seawater $\left(\mathrm{g} \mathrm{m}^{-3}\right)$

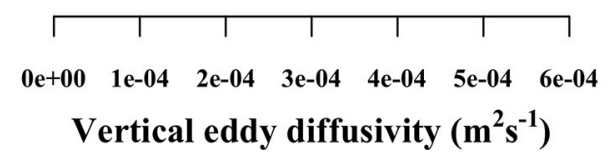

M. longa density (ind $\mathrm{m}^{-3}$ )

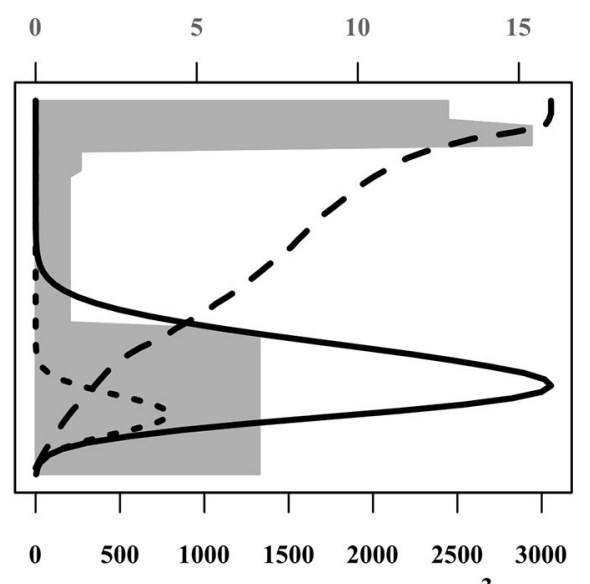

Egg concentration $\left(\mathrm{egg} \mathrm{m}^{-3}\right)$

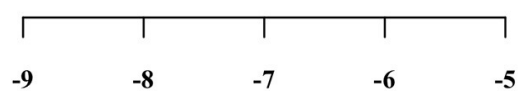

Egg velocity $\left(\mathrm{m} \mathrm{d}^{-\mathbf{1}}\right)$

FIGURE 4 | Example of in situ physical forcing profiles from Amundsen Gulf used in the egg vertical distribution simulation (left panel). Solid line is the vertical eddy diffusivity $\left(\mathrm{m}^{2} \mathrm{~s}^{-1}\right)$, dashed line is the density anomaly of seawater $\left(\mathrm{g} \mathrm{m}^{-3}\right)$ and dotted line is the temperature $\left({ }^{\circ} \mathrm{C}\right)$. Corresponding egg concentrations simulated for mean egg density (scenario $D_{0}$ ) of $19.4 \mathrm{~kg} \mathrm{~m}^{-3}$ are presented in the right panel. Dashed line is the egg velocity $\left(\mathrm{m} \mathrm{d}^{-1}\right)$ computed according to Stokes' law. Dotted line is at the initial condition corresponding to the spawned eggs profile. Solid line is the egg concentration distribution after 15 days of simulation. Gray area is the female $M$. longa abundance (ind $\mathrm{m}^{-3}$ ).

their daily metabolic needs from egg grazing. This asymmetric and widely spread distribution has a geometric coefficient of variation of $149 \%$. This pattern is consistent across the range of incubation conditions we tested, and this level of variability is common in any experimental setting measuring individual biological features (size, structural or storage weight, swimming behavior, etc.) and physiological rates (respiration, ingestion, growth, etc.) (e.g., Basedow and Tande, 2006). We do not have clear explanations for the level of variability we observed, but it is a useful observation to report (see Supplementary Material for a spreadsheet of individual observations). Individual variability has long been recognized as a key property of plankton ecology since population dynamics and trophic interactions (that are of primary interest for marine ecologists) are emerging properties of individual characteristics and behaviors (Båmstedt, 1988). Modern experimental and in situ observation methods 


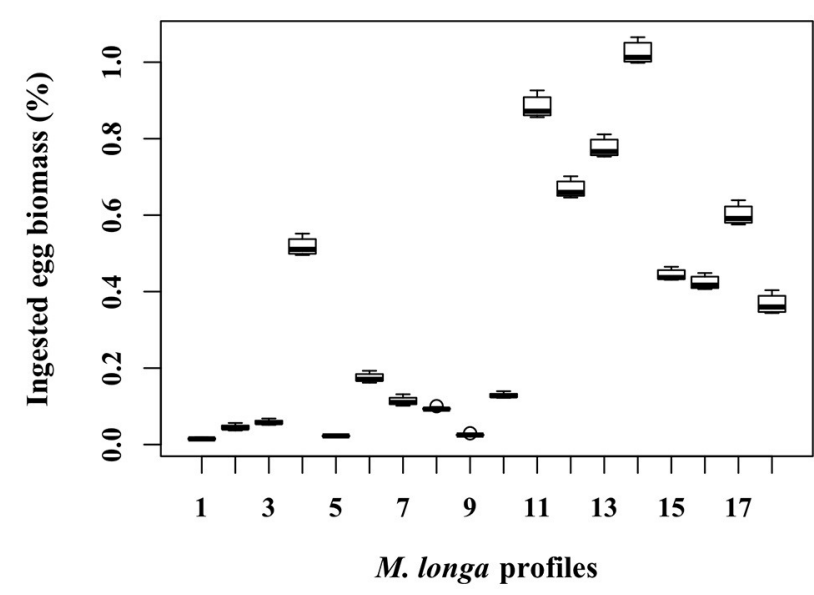

FIGURE 5 | Proportion of C. hyperboreus egg standing stock (\%) ingested by female $M$. longa for all the $\mathbf{3 6 0}$ simulations with mean egg density (scenario $D_{0}$ ) and grouped according to each of the 18 in situ female $M$. longa abundance profiles.

are providing increasingly detailed and abundant individuallevel data (e.g., Schmid et al., 2016), while current numerical approaches allow for testing how and how well individual-based models can effectively represent emerging properties at higher organizational levels (Neuheimer et al., 2010; Morozov et al., 2013).

\section{Dynamical Interactions in the Water Column}

This modeling exercise provided insight on the physical and biological dynamical processes interacting in the water column and their relative importance for the vertical distribution of C. hyperboreus eggs.

We first performed a scale analysis of the two first terms on the right-hand side of Equation (7), i.e., egg buoyancy and vertical turbulence. For the simulation scenario illustrated in Figure 4, we can estimate the vertical gradient in egg concentration $\frac{\partial \mathrm{E}}{\partial \mathrm{z}} \approx 15$ egg $\mathrm{m}^{-4}$ near the maximum egg concentration at $250 \mathrm{~m}$ (an approximate increase of $750 \mathrm{egg} \mathrm{m}^{-3}$ over $50 \mathrm{~m}$ ) and $\frac{\partial^{2} \mathrm{E}}{\partial \mathrm{z}^{2}} \approx 1 \mathrm{egg}$ $\mathrm{m}^{-5}$ ( $\frac{\partial \mathrm{E}}{\partial \mathrm{z}}$ varies between \pm 15 egg $\mathrm{m}^{-3}$ over about $30 \mathrm{~m}$ from both sides of the maximum concentration), simple arithmetic suggests that

$$
w \frac{\partial \mathrm{E}}{\partial \mathrm{z}} \approx[1,3] \times 10^{-3} \mathrm{egg} \mathrm{m}^{-3} \mathrm{~s}^{-1}
$$

and

$$
K \frac{\partial^{2} \mathrm{E}}{\partial \mathrm{z}^{2}} \approx 10^{-5} \mathrm{egg} \mathrm{m}^{-3} \mathrm{~s}^{-1}
$$

with $w \in[4,9.3] \mathrm{m} \mathrm{d}^{-1}$ (see Results) and $K=3.4 \times 10$ $\mathrm{m}^{-6} \mathrm{~s}^{-1}$ (background turbulent diffusivity) from (Bourgault et al., 2011). This suggest that from a physical point of view, the buoyant vertical displacement of eggs is dominant over the turbulent diffusion mechanism, and only turbulent events about a 100 times above the background value could effectively influence their distribution. The role of turbulent mixing in egg distribution (aggregation or spreading) is likely minimal and the use of a parameterization such as the one presented in Bourgault et al. (2011) could have been sufficient here. The effect of turbulence may only become important for denser eggs rising very slowly toward the surface or directly after the spawning if it occurs in a thin layer pattern, hence producing a high concentration gradient. This effect could be studied more efficiently with new in situ sampling devices such as the LOKI underwater imaging system that can provide highly resolved vertical distribution of adult females C. hyperboreus, their eggs, a whole suite of potential other intraguild predators beyond $M$. longa and the physical properties of the water column as well (Schmid et al., 2016).

From a biological point of view, egg density had an overwhelming impact on egg vertical distribution patterns (Figure 7). Egg density defined their vertical velocity $w$ and as a result both the range of depth they could reach before hatching and their corresponding concentration. For two out of three egg density scenarios, eggs laid at depth did not manage to reach and accumulate within the surface layer. Even for the minimum density scenario $D_{\min }$, the amount of eggs reaching the surface remained marginal. This is coherent with the generally accepted idea that $C$. hyperboreus nauplii, rather than eggs, accumulate under the ice in advance of the phytoplankton bloom (Conover and Huntley, 1991). Meanwhile, the maximum egg concentration reached was about 4 eggs $\mathrm{L}^{-1}$, close the minimal egg concentration used in our grazing experiments. Depth and concentration were crucial for the interaction with female $M$. longa whose vertical position and abundance vary a lot, and whose ingestion rate depends on the surrounding egg concentration. As a result, it appeared that the probability of encounter between a predator and an egg of C. hyperboreus was determined essentially by the density of the latter.

\section{Impact of Intraguild Predation on C. hyperboreus Recruitment}

If we consider thin layer effects to remain marginal, our results suggest that impacts on $C$. hyperboreus population dynamics may remain limited in space and time since $M$. longa IGP was limited to a little more than $3 \%$ of $C$. hyperboreus egg biomass. However, young nauplii stages could also be preyed upon by $M$. longa and thus our figures could underestimate the actual impact of $M$. longa on C. hyperboreus recruitment. $M$. longa is a cruising feeder, i.e., it cruises through water searching for food and prey and captures them upon detection. Moreover, motile preys such as nauplii can generate a hydrodynamic trail while swimming that could render them be easier to detect by $M$. longa than nonmotile preys such as eggs (Kiørboe, 2011). This assumption is supported by feeding experiments with $M$. lucens and M. longa in which phytoplankton and much larger nauplii Artemia were offered together, illustrating selective feeding on Artemia nauplii (Haq, 1967).

In addition to females $M$. longa, other development stages of this species and other copepod species could also exert IGP on 


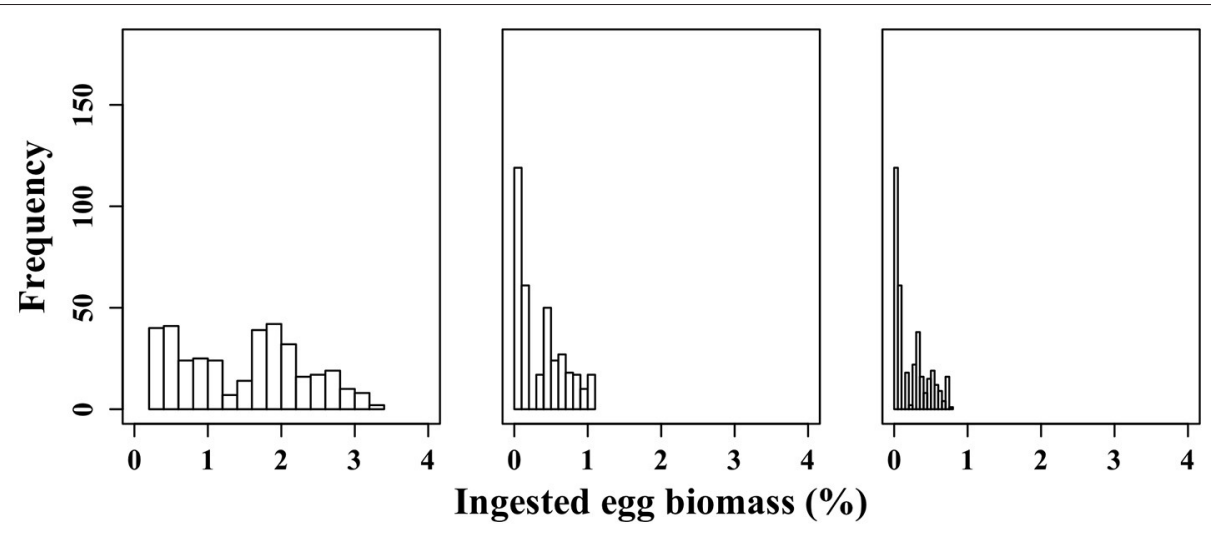

FIGURE 6 | Frequency distribution of the proportion of C. hyperboreus eggs standing stock ingested by female $M$. longa according to the minimal $\left(0.6 \mathrm{~kg} \mathrm{~m}^{-3}\right)$ (scenario $D_{\min }$ ) (left panel), mean $\left(19.4 \mathrm{~kg} \mathrm{~m}^{-3}\right)$ (scenario $\left.D_{0}\right)$ (middle panel) and maximal C. hyperboreus egg density (26.8 $\mathrm{kg} \mathrm{m}^{-3}$ ) (scenario $D_{\max }$ ) (right panel).

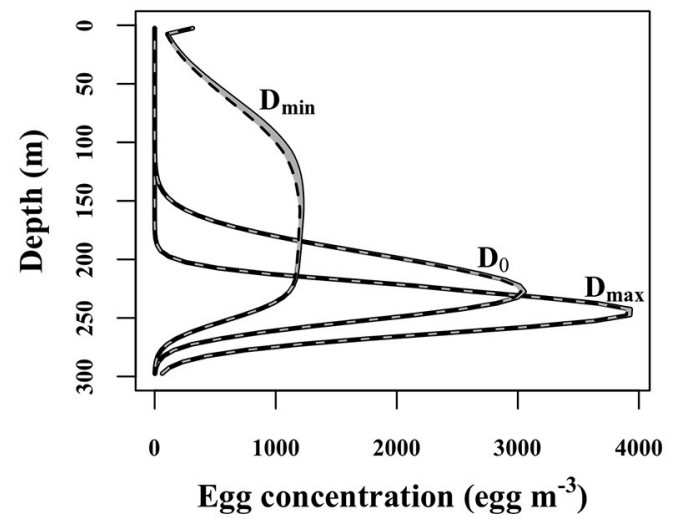

Proportion of daily metabolism (\%)

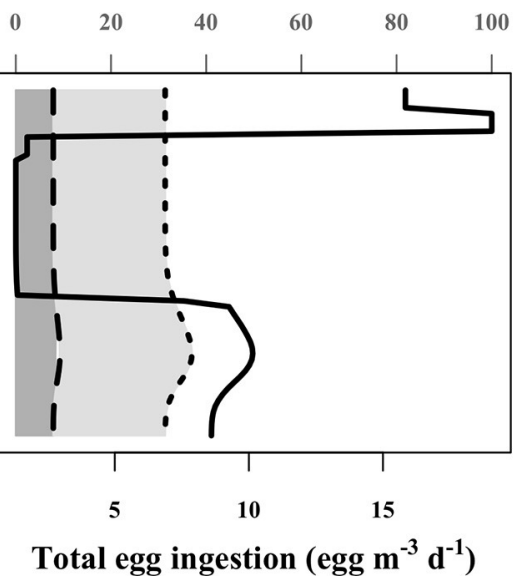

FIGURE 7 | Simulated egg concentration profiles for three different scenarios (scenario $\mathbf{D}_{\min }$, $\mathbf{D}_{\mathbf{0}}$, and $\mathbf{D}_{\text {max; }}$ left panel). Solid line is without female M. longa intraguild predation, dashed line is with intraguild predation and the gray area is the difference between both. On the right panel, solid line is the C. hyperboreus egg biomass ingested by the population of female $M$. longa (egg m $\mathrm{m}^{-3} \mathrm{~d}^{-1}$ ) according to the simulated egg concentration with scenario $D_{0}$ and M. longa abundance profile presented in Figure 4. Proportion of individual daily metabolic needs satisfied by egg ingestion (\%) according to respiration rates from Seuthe et al. (2006; Dashed line) and Hirche (1987; Dotted line).

C. hyperboreus eggs. As already mentioned, adults and advanced copepodite stages of the large C. glacialis emerge from diapause and initiate ascent to surface layers prior the spring bloom to feed on ice algae (Daase et al., 2013). Therefore, they could also benefit from the energy rich $C$. hyperboreus eggs (and potentially the nauplii) and add to the predation pressure. Thus, we likely have underestimated IGP pressure on C. hyperboreus and its impact on its recruitment in several ways. However, it may remain very dependent on the seasonal timing of the feeding activity of these potential predators, as well as their vertical position in the water column as already demonstrated.

It seems that there is actually an ecological trade-off for C. hyperboreus females to lay low (lipid-rich) or high-density (lipid-poor) eggs. On one hand the obvious metabolic advantage for lipid-rich eggs is that the offspring can rely on abundant reserves to develop. The downside however could be that low-density eggs reach faster and "en masse" the layer where $M$. longa and other species are abundant, hence increasing their mortality risk. On the other hand, dense eggs ascend very slowly and actually hatch before having reached these dangerous depths. The wide range in egg density that has been observed among eggs from different $C$. hyperboreus females but also within the same egg clutch (Jung-Madsen et al., 2013) could actually be part of a strategy that mitigates predation risk by spreading the eggs across a range of ascent speeds. However, the delicate balance of both opposing effects on offspring fitness could only be assessed in a more detailed modeling study supported by finely resolved and 
concurrent observation of the zooplankton community vertical distribution.

\section{C. hyperboreus Importance in the Arctic System}

Our results could offer an interesting contrast with the earlier study of Huntley and Escritor (1992) on a couple of homologous species from Antarctica, M. gerlachei and C. acutus. They showed from incubations of a group of individuals that $M$. gerlachei could reach daily rations ranging between 4 to $11 \%$ of its body weight when offered 1000 egg $\mathrm{L}^{-1}$. The authors further estimated that this concentration was about three orders of magnitude higher than what it could be in situ $\left(1\right.$ egg $\left.\mathrm{L}^{-1}\right)$ and thus concluded that this type of predation is likely insignificant. However, our experimental results showed that $M$. longa individuals could meet up to $75 \%$ of their daily metabolic requirements on eggs of C. hyperboreus offered at a concentration of $5 \mathrm{~L}^{-1}$, based on respiration rates observed in Amundsen Gulf (Seuthe et al., 2006). We also simulated that the mean in situ ration of eggs for $M$. longa females should vary between 8 and $37 \%$ of their metabolic needs, depending on the respiration rate. The lower boundary is based on Seuthe et al. (2006), whereas the upper boundary is based on lower respiration rates (Hirche, 1987). Neither value is sufficient to ensure complete metabolic maintenance, but during wintertime it could be combined to some level of lipid stores to cope with the otherwise scarce food background available to these copepods. Lipid-rich C. hyperboreus eggs (and potentially nauplii) are a reliable and valuable food source that at least some $M$. longa individuals seem prone to take advantage of during several months of the year.

Our study stresses the importance of C. hyperboreus as a linchpin of Arctic marine trophic network. This key species has adapted to the extreme environment by evolving its ability to store considerable amounts of lipids. C. hyperboreus efficiently concentrate the energy from the short-lived primary production bloom and supports the entire marine trophic network. Higher trophic levels rely heavily on its large copepodite and adult development stages, while zooplankton species from a similar trophic level (from the same guild) also benefit from the smaller packaging of the bounty within its eggs. Moreover, since C. hyperboreus reproduction occurs for several months during a period of the polar year when primary production has shut down, it likely provides a precious and unparalleled resource for several species of planktonic predators that remain active in the dead of winter. Hence, IGP should not only be considered as an extra mortality source that could affect recruitment of the species that is preyed upon, but also as a crucial survival strategy that could shape the life cycle strategies of some opportunistic species.

IGP needs to be studied further as we move toward an integrated approach of marine ecology that recognizes the influence of both individual variability and community-level interactions. Other implications of IGP than those evoked in our study could be important. In the North Atlantic for example, the survival of $C$. finmarchicus early stages follows different seasonal patterns in areas where it is the dominant Calanus species than in areas where its larger congeners, C. glacialis and $C$. hyperboreus, co-occur. In such areas where all three species live together, the C. finmarchicus recruitment peak can occur several weeks after the spring bloom, much later than it usually does (Melle et al., 2014). In early spring, C. hyperboreus and C. glacialis, that are already active when C. finmarchicus initiates its reproduction fuelled by the phytoplankton bloom, could ingest $C$. finmarchicus eggs and affect its recruitment. Interestingly, IGP could contribute to the resistance of marginal Arctic marine ecosystems to the northward advance of the boreal C. finmarchicus under the pressure of climate change.

\section{AUTHOR CONTRIBUTIONS}

KD designed and ran the laboratory experiments, participated to the in situ sampling, did the statistical analysis, ran the modeling experiment, and wrote most of the paper. FM contributed to the design of the laboratory experiment, contributed to the data analysis, designed, and executed most of the modeling experiment and contributed to the writing. SP contributed to the design of the laboratory experiment, provided access to the laboratory facility, and contributed to the writing. PJ contributed to the design and the execution of the laboratory experiment, and ran the in situ sampling. FC contributed to the design of the numerical experiment, provided data from Amundsen Gulf, and contributed to the writing.

\section{FUNDING}

This work has been supported by an NSERC Discovery grant to FM, DFO, and Québec-Océan.

\section{ACKNOWLEDGMENTS}

$\mathrm{KD}$ is grateful to $\mathrm{PJ}$ for his invaluable help in the field and in the laboratory, Geneviève Parent for her help with image analysis, Michel Starr and Liliane St-Amand for their help with laboratory analysis, David Levasseur for his assistance in the laboratory experiments and Daniel Bourgault for the Amundsen Gulf physical data. KD also thanks FM, SP, and Maurice Levasseur for the stimulating and constructive discussions and finally FC and Jeffrey Runge for their help on the manuscript. This is a contribution to the research programs of Québec-Océan, ArcticNet and UMI Takuvik.

\section{SUPPLEMENTARY MATERIAL}

The Supplementary Material for this article can be found online at: http://journal.frontiersin.org/article/10.3389/fmars. 2016.00185

The $\mathrm{R}$ code and forcing fields for the model can be found online at: https://github.com/NEOLab-Git/Chyp_Egg_1D.git

The detailed table of individual observations is provided. 


\section{REFERENCES}

Arim, M., and Marquet, P. A. (2004). Intraguild predation: a widespread interaction related to species biology. Ecol. Lett. 7, 557-564. doi: 10.1111/j.14610248.2004.00613.x

Båmstedt, U. (1988). Ecological significance of individual variability in copepod bioenergetics. Hydrobiologia 167-168, 43-59. doi: 10.1007/BF00026293

Båmstedt, U., Gifford, D. J., Irigoien, X., Atkinson, A., and Roman, M. (2000). "Feeding", in ICES Zooplankton Methodology Manual, eds R. Harris, P. Wiebe, J. Lenz, H.-R. Skjoldal, and M. Huntley (Plymouth: Academic Press), 297-399.

Barber, D. G., Asplin, M. G., Gratton, Y., Lukovich, J. V., Galley, R. J., Raddatz, R. L., et al. (2011). The International polar year (IPY) circumpolar flaw lead (CFL) system study: overview and the physical system. Atmosphere Ocean 48, 225-243. doi: 10.3137/OC317.2010

Basedow, S., and Tande, K. (2006). Cannibalism by female Calanus finmarchicus on naupliar stages. Mar. Ecol. Prog. Ser. 327, 247-255. doi: 10.3354/meps327247

Bonnet, D. (2004). Calanus the cannibal. J. Plankton Res. 26, 937-948. doi: 10.1093/plankt/fbh087

Bourgault, D., Hamel, C., Cyr, F., Tremblay, J. É., Galbraith, P. S., Dumont, D., et al. (2011). Turbulent nitrate fluxes in the Amundsen Gulf during ice-covered conditions. Geophys. Res. Lett. 38, L15602. doi: 10.1029/2011GL047936

Carmack, E. C., and Macdonald, R. W. (2002). Oceanography of the Canadian Shelf of the Beaufort Sea: a setting for marine life. Arctic 55, 29-45. doi: $10.14430 / \operatorname{arctic} 733$

Conover, R. J., and Huntley, M. (1991). Copepods in ice-covered seas - distribution, adaptations to seasonally limited food, metabolism, growth patterns and life cycle strategies in polar seas. J. Mar. Syst. 2, 1-41. doi: 10.1016/09247963(91)90011-I

Daase, M., Falk-Petersen, S., Varpe, Ø., Darnis, G., Søreide, J. E., Wold, A., et al. (2013). Timing of reproductive events in the marine copepod Calanus glacialis: a Pan-Arctic perspective. Can. J. Fish. Aqua. Sci. 14, 1-14. doi: 10.1139/cjfas2012-0401

Darnis, G. (2013). Migration Verticale du Zooplancton et flux Respiratoire de Carbone en mer de Beaufort (Arctique Canadien). Thesis, Université Laval, Québec, QC.

Darnis, G., and Fortier, L. (2014). Temperature, food and the seasonal vertical migration of key arctic copepods in the thermally stratified Amundsen Gulf (Beaufort Sea, Arctic Ocean). J. Plankton Res. 36, 1092-1168. doi: 10.1093/ plankt/fbu035

Darnis, G., Robert, D., Pomerleau, C., Link, H., Archambault, P., Nelson, R. J., et al. (2012). Current state and trends in Canadian Arctic marine ecosystems: II. Heterotrophic food web, pelagic-benthic coupling, and biodiversity. Clim. Change 115, 179-205. doi: 10.1007/s10584-012-0483-8

Davis, C. S. (1984). Predatory control of copepod seasonal cycles on Georges Bank. Mar. Biol. 82, 31-40. doi: 10.1007/BF00392761

Falardeau, M., Robert, D., and Fortier, L. (2013). Could the planktonic stages of polar cod and Pacific sand lance compete for food in the warming Beaufort Sea? ICES J. Mar. Sci. 71, 1956-1965. doi: 10.1093/icesjms/fst221

Forest, A., Galindo, V., Darnis, G., Pineault, S., Lalande, C., Tremblay, J. E., et al. (2010). Carbon biomass, elemental ratios (C:N) and stable isotopic composition $\left({ }^{13} \mathrm{C},{ }^{15} \mathrm{~N}\right)$ of dominant calanoid copepods during the winter-tosummer transition in the Amundsen Gulf (Arctic Ocean). J. Plankton Res. 33, 161-178. doi: 10.1093/plankt/fbq103

Fort, J., Cherel, Y., Harding, A. M. A., Welcker, J., Jakubas, D., Steen, H., et al. (2010). Geographic and seasonal variability in the isotopic niche of little auks. Mar. Ecol. Prog. Ser. 414, 293-302. doi: 10.3354/meps08721

Galley, R. J., Key, E., Barber, D. G., Hwang, B. J., and Ehn, J. K. (2008). Spatial and temporal variability of sea ice in the southern Beaufort Sea and Amundsen Gulf: 1980-2004. J. Geophys. Res. Oceans 113, 1-18. doi: 10.1029/2007jc004553

Gentleman, W. C., Neuheimer, A. B., and Campbell, R. G. (2008). Modelling copepod development: current limitations and a new realistic approach. ICES J. Mar. Sci. 65, 399-413. doi: 10.1093/icesjms/fsn047

Greene, C. H., and Pershing, A. J. (2014). The flip-side of the North Atlantic Oscillation and modal shifts in slope-water circulation patterns. Limnol. Oceanogr. 48, 319-322. doi: 10.4319/lo.2003.48.1.0319

Haq, S. M. (1967). Nutritional physiology of Metridia lucens and M. longa from the Gulf of Maine. Limnol. Oceanogr. 12, 40-51. doi: 10.4319/lo.1967.12.1.0040
Head, E. J. H., Harris, L. R., and Yashayaev, I. (2003). Distributions of Calanus spp. and other mesozooplankton in the Labrador Sea in relation to hydrography in spring and summer (1995-2000). Prog. Oceanogr. 59, 1-30. doi: 10.1016/S00796611(03)00111-3

Hiltunen, T., Jones, L. E., Ellner, S. P., and Hairston, N. G. (2013). Temporal dynamics of a simple community with intraguild predation: an experimental test. Ecology 94, 773-779. doi: 10.1890/12-0786.1

Hirche, H. J. (1987). Temperature and plankton II. Effect on respiration and swimming activity in copepods from the Greenland Sea. Mar. Biol. 94, 347-356. doi: 10.1007/BF00428240

Holt, R. D., and Polis, G. A. (1997). A theoretical framework for intraguild predation. Am. Nat. 149, 745-764. doi: 10.1086/286018

Hopcroft, R. R., Kosobokova, K. N., and Pinchuk, A. I. (2010). Zooplankton community patterns in the Chukchi Sea during summer 2004. Deep Sea Res. Part II: Top. Stud. Oceanogr. 57, 27-39. doi: 10.1016/j.dsr2.2009.08.003

Huntley, M. E., and Escritor, F. (1992). Ecology of Metridia gerlachei Giesbrecht in the western Bransfield Strait, Antarctica. Deep Sea Res. Part A Oceanogr. Res. Pap. 39, 1027-1055. doi: 10.1016/0198-0149(92)90038-U

Irigoien, X., and Harris, R. P. (2006). Comparative population structure, abundance and vertical distribution of six copepod species in the North Atlantic: evidence for intraguild predation? Mar. Biol. Res. 2, 276-290. doi: $10.1080 / 17451000600865321$

Jung-Madsen, S., Nielsen, T. G., Grønkjaer, P., Hansen, B. W., and Møller, E. F. (2013). Early development of Calanus hyperboreus nauplii: response to a changing ocean. Limnol. Oceanogr. 58, 2109-2121. doi: 10.4319/lo.2013.58. 6.2109

Kiørboe, T. (2011). How zooplankton feed: mechanisms, traits and trade-offs. Biol. Rev. Camb. Philos. Soc. 86, 311-339. doi: 10.1111/j.1469-185X.2010.00148.x

Kiørboe, T. (2013). Attack or attacked: the sensory and fluid mechanical constraints of copepods' predator-prey interactions. Integr. Comp. Biol. 53, 821-831. doi: 10.1093/icb/ict021

Kwasniewski, S., Gluchowska, M., Jakubas, D., Wojczulanis-Jakubas, K., Walkusz, W., Karnovsky, N., et al. (2010). The impact of different hydrographic conditions and zooplankton communities on provisioning Little Auks along the West coast of Spitsbergen. Prog. Oceanogr. 87, 72-82. doi: 10.1016/j.pocean. 2010.06.004

Landry, M. R. (1981). Switching Between Herbivory and Carnivory by the Planktonic Marine Copepod Calanus pacificus. Mar. Biol. 65, 77-82. doi: 10.1007/BF00397070

Lee, R. F., Hagen, W., and Kattner, G. (2006). Lipid storage in marine zooplankton. Mar. Ecol. Prog. Ser. 307, 273-306. doi: 10.3354/meps307273

Le Fouest, V., Lefouest, V., Zakardjian, B., Saucier, F. J., and Starr, M. (2005). Seasonal versus synoptic variability in planktonic production in a high-latitude marginal sea: The Gulf of St. Lawrence (Canada). J. Geophys. Res. C Oceans 110, 1-21. doi: 10.1029/2004JC002423

Melle, W., Runge, J., Head, E., Plourde, S., Castellani, C., Licandro, P., et al. (2014). The North Atlantic Ocean as habitat for Calanus finmarchicus: environmental factors and life history traits. Prog. Oceanogr. 129, 244-284. doi: 10.1016/j.pocean.2014.04.026

Menden-Deuer, S., and Lessard, E. J. (2000). Carbon to volume relationships for dinoflagellates, diatoms, and other protist plankton. Limnol. Oceanogr. 45, 569-579. doi: 10.4319/lo.2000.45.3.0569

Mills, K. E., Pershing, A. J., Sheehan, T. F., and Mountain, D. (2013). Climate and ecosystem linkages explain widespread declines in North American Atlantic salmon populations. Glob. Chang. Biol. 19, 3046-3061. doi: 10.1111/gcb.12298

Morozov, A., Pasternak, A. F., and Arashkevich, E. G. (2013). Revisiting the role of individual variability in population persistence and stability. PLoS ONE 8:e70576. doi: 10.1371/journal.pone.0070576

Neuheimer, A. B., Gentleman, W. C., Pepin, P., and Head, E. J. H. (2010). How to build and use individual-based models (IBMs) as hypothesis testing tools. J. Mar. Syst. 81, 122-133. doi: 10.1016/j.jmarsys.2009.12.009

Ohman, M. D., and Hirche, H. J. (2001). Density-dependent mortality in an oceanic copepod population. Nature 412, 638-641. doi: 10.1038/35088068

Ohman, M., Eiane, K., Durbin, E., Runge, J., and Hirche, H. (2004). A comparative study of Calanus finmarchicus mortality patterns at five localities in the North Atlantic. ICES J. Mar. Sci. 61, 687-697. doi: 10.1016/j.icesjms.2004. 03.016 
Plourde, S., Dodson, J. J., Runge, J. A., and Therriault, J. C. (2002). Spatial and temporal variations in copepod community structure in the lower St. Lawrence Estuary, Canada. Mar. Ecol. Prog. Ser. 230, 211-224. doi: 10.3354/meps 230211

Plourde, S., Joly, P., Runge, J. A., Dodson, J., and Zakardjian, B. (2003). Life cycle of Calanus hyperboreus in the lower St. Lawrence Estuary and its relationship to local environmental conditions. Mar. Ecol. Prog. Ser. 255, 219-233. doi: 10.3354/meps 255219

Plourde, S., Maps, F., and Joly, P. (2009). Mortality and survival in early stages control recruitment in Calanus finmarchicus. J. Plankton Res. 31, 371-388. doi: 10.1093/plankt/fbn126

Polis, G. A., Myers, C. A., and Holt, R. D. (1989). The ecology and evolution of intraguild: potential competitors that eat each other. Annu. Rev. Ecol. Syst. 20, 297-330. doi: 10.1146/annurev.es.20.110189.001501

Pomerleau, C., Lesage, V., Winkler, G., Rosenberg, B., and Ferguson, S. H. (2014). Contemporary diet of bowhead whales (Balaena mysticetus) from the Eastern Canadian Arctic inferred from fatty acid biomarkers. Arctic 67, 84. doi: $10.14430 / \operatorname{arctic} 4366$

Record, N. R., and Pershing, A. J. (2008). Modeling zooplankton development using the monotonic upstream scheme for conservation laws. Limnol. Oceanogr. Methods 6, 364-372. doi: 10.4319/lom.2008.6.364

Record, N. R., Pershing, A. J., and Maps, F. (2012). First principles of copepod development help explain global marine diversity patterns. Oecologia 170 , 289-295. doi: 10.1007/s00442-012-2313-0

Record, N. R., Pershing, A. J., and Maps, F. (2013). Emergent copepod communities in an adaptive trait-structured model. Ecol. Model. 260, 11-24. doi: 10.1016/j.ecolmodel.2013.03.018

Reygondeau, G., and Beaugrand, G. (2011). Future climate-driven shifts in distribution of Calanus finmarchicus. Glob. Chang. Biol. 17, 756-766. doi: 10.1111/j.1365-2486.2010.02310.x
Saucier, F. J., Roy, F., and Gilbert, D. (2003). Modeling the formation and circulation processes of water masses and sea ice in the Gulf of St. Lawrence, Canada. J. Geophys. Res. 3269, 2501-2520. doi: 10.1029/2000jc000686

Schmid, M. S., Aubry, C., Grigor, J., and Fortier, L. (2016). The LOKI underwater imaging system and an automatic identification model for the detection of zooplankton taxa in the Arctic Ocean. Methods Oceanogr. 160, 129-160. doi: 10.1016/j.mio.2016.03.003

Seuthe, L., Darnis, G., Riser, C. W., Wassmann, P., and Fortier, L. (2006). Winterspring feeding and metabolism of Arctic copepods: insights from faecal pellet production and respiration measurements in the southeastern Beaufort Sea. Polar Biology 30, 427-436. doi: 10.1007/s00300-006-0199-1

Soetaert, K., and Herman, P. M. J. (2009). A Practical Guide to Ecological Modelling. Dordrecht: Springer.

Vestheim, H., Brucet, S., and Kaartvedt, S. (2013). Vertical distribution, feeding and vulnerability to tactile predation in Metridia longa (Copepoda, Calanoida). Mar. Biol. Res. 9, 949-957. doi: 10.1080/17451000.2013.793806

Visser, A. W. W., and Jónasdóttir, S. H. (1999). Lipids, buoyancy and the seasonal vertical migration of Calanus finmarchicus. Fish. Oceanogr. 8, 100-106. doi: 10.1046/j.1365-2419.1999.00001.x

Conflict of Interest Statement: The authors declare that the research was conducted in the absence of any commercial or financial relationships that could be construed as a potential conflict of interest.

Copyright $\odot 2016$ Dufour, Maps, Plourde, Joly and Cyr. This is an open-access article distributed under the terms of the Creative Commons Attribution License (CC BY). The use, distribution or reproduction in other forums is permitted, provided the original author(s) or licensor are credited and that the original publication in this journal is cited, in accordance with accepted academic practice. No use, distribution or reproduction is permitted which does not comply with these terms. 